\title{
Stopover departure decisions in songbirds: do long-distance migrants depart earlier and more independently of weather conditions than medium-distance migrants?
}

\author{
Florian Packmor ${ }^{1,2^{*}}$, Thomas Klinner ${ }^{1}$, Bradley K. Woodworth ${ }^{3}$, Cas Eikenaar ${ }^{1}$ and Heiko Schmaljohann ${ }^{1,4}$
}

\begin{abstract}
Background: Songbirds following distinct migration strategies (e.g. long- vs. short- to medium-distance migrants) often differ in their speed of migration during autumn and, thus, are assumed to face different time constraints. During migration, most songbird species alternate migratory flights with stopover periods. Many of them restrict these migratory flights to the night, i.e., they are nocturnal migrants. At stopover, nocturnal migrants need to select a specific night (night-to-night decision) and time of night (within-night decision) to resume migration. These departure decisions, which largely determine the speed of migration, are jointly affected by a set of intrinsic and extrinsic factors, i.e., departure cues. Here we aim to assess whether the set of intrinsic and extrinsic factors and the magnitude of their respective effects on stopover departure decisions differs between nocturnally migrating songbird species, depending on their migration strategy and associated time constraints.

Methods: We radio-tracked migrating Northern Wheatears (Oenanthe oenanthe; long-distance migrant), European robins (Erithacus rubecula) and Common Blackbirds (Turdus merula; both medium-distance migrants) during autumn stopover and analysed their night-to-night and within-night departure timing in relation to intrinsic and extrinsic factors.

Results: Species generally differed in their departure timing on both temporal scales, with shortest stopovers and earliest nocturnal departures in the long-distance migrant. Some factors, such as day of year, fuel load, cloud cover and crosswind, had consistent effects on stopover departure decisions in all three species. However, species differed in the effects of tailwind assistance, change in atmospheric pressure and air temperature on their stopover departure decisions. Whereas night-to-night decisions were affected by these extrinsic factors in either both or one of the medium-distance migrants, such effects were not found in the long-distance migrant.

Conclusions: Our results suggest that the general timing of departures in songbirds is affected by the species-specific migration strategy and associated time constraints. Further, they imply that the assessment and usage of specific extrinsic factors, i.e., weather conditions, as departure cues is adjusted based on this migration strategy, with the long-distance migrants being least selective at departure. Other intrinsic and extrinsic factors, however, seem to be used as departure cues independent of migration strategy.
\end{abstract}

Keywords: Departure decision, Departure timing, Fuel load, Long-distance migration, Medium-distance migration, Songbird, Weather conditions

\footnotetext{
* Correspondence: f.packmor@bangor.ac.uk

'Institute of Avian Research "Vogelwarte Helgoland", An der Vogelwarte 21,

26386 Wilhelmshaven, Germany

${ }^{2}$ School of Natural Sciences, Bangor University, Deiniol Road, Bangor LL57

2UW, UK

Full list of author information is available at the end of the article
}

(c) The Author(s). 2020 Open Access This article is distributed under the terms of the Creative Commons Attribution 4.0 International License (http://creativecommons.org/licenses/by/4.0/), which permits unrestricted use, distribution, and reproduction in any medium, provided you give appropriate credit to the original author(s) and the source, provide a link to the Creative Commons license, and indicate if changes were made. The Creative Commons Public Domain Dedication waiver (http://creativecommons.org/publicdomain/zero/1.0/) applies to the data made available in this article, unless otherwise stated. 


\section{Background}

Billions of songbirds migrate between their breeding areas and wintering grounds by alternating periods of migratory flight with stopover periods that serve to rest and fuel. Since a songbird's rate of energy accumulation is far slower than their rate of energy expenditure during flight $[1,2]$, they actually spend more time and energy during stopovers than during migratory flights [3, 4]. Total stopover duration, thus, strongly influences songbirds' overall speed of migration $[5,6]$. Travel speed, defined as total migration distance divided by total flight duration, is the other main determinant of overall speed of migration [7]. Many migratory songbirds restrict their migratory flights to the night (e.g. $[8,9])$. Hence, their nocturnal departure timing defines the potential flight duration and the associated distance per flight bout [10, 11]. A bird's decisions on which night to depart (nightto-night departure decision) and the exact time of departure within the night (within-night departure decision) thus directly affect its overall speed of migration and, consequently, its time of arrival at the migratory destination. Studying how individuals adjust these decisions advances our understanding of variation in arrival timing and its potential consequences for individual survival and fitness [12-14].

It is assumed that the fundamental spatiotemporal organisation of migration in songbirds is governed by an innate migration program, which provides the basis for timing, duration and direction of migration as well as for physiological adaptations associated with migratory behaviour (e.g. [15-18]). This innate migration program further defines the birds' behavioural reaction norms to variation in different intrinsic and extrinsic factors (e.g. $[19,20])$. There is substantial evidence that day of year (time within season; intrinsic factor), fuel load (energy stores; intrinsic factor), and prevailing weather conditions (extrinsic factors) affect night-to-night and withinnight departure decisions and, thus, probably act as departure cues for migratory birds (e.g. [20-28]). The exact set of cues used by the birds and the magnitude of their respective effects seem to vary within- and betweenspecies, probably because departure decisions are flexibly adjusted over time and space [19] and because species' migration strategies differ in terms of time and/or energy constraints [29].

Migration is a complex phenomenon with remarkable inter- and intra-specific variation in the respective strategies. These strategies include both facultative and obligate migrations ranging over tens, hundreds or thousands of kilometres [30]. In the Africa-Eurasia flyway system songbirds performing obligate migrations are commonly categorised as either short- to mediumdistance migrants (migrating predominantly within Eurasia), or long-distance migrants (migrating between
Eurasia and tropical sub-Saharan Africa, i.e., transSaharan migrants). Long-distance migrants are assumed to face relatively strong time constraints to complete their migratory journey. Thus, they are probably selected to maximise speed of migration at the expense of relatively high energetic costs to reach their distant destinations in a reasonable time [1]. In short- to mediumdistance migrants, by contrast, selection for the maximisation of speed is probably less pronounced and these birds may be more prone to minimize energy expenditure during migration, at least in autumn [29, 31, 32]. Accordingly, short- to medium-distance migrants and long-distance migrants should feature different behavioural reaction norms to intrinsic and extrinsic factors in autumn, i.e., they should differ in the use of specific cues for their departure decisions during stopover. There is some evidence that short- to medium-distance migrants travel, for example, with more favourable winds [29], but show a lower speed of migration than long-distance migrants $[1,33,34]$. So far, however, we lack detailed knowledge about how intrinsic and extrinsic factors may differently affect night-to-night and within-night departure decisions in birds facing different migration distances.

Here, we investigate the timing of migratory departures in one long-distance migrant, the Northern Wheatear (Oenanthe oenanthe; Wheatear hereafter), and two mediumdistance migrants, the European Robin (Erithacus rubecula; Robin hereafter) and the Common Blackbird (Turdus merula; Blackbird hereafter), from a coastal stopover site in Central Europe during autumn, when these species differ in distance to their migratory destinations (Fig. 1). All analyses are based on individual migratory departure data obtained by means of automated radio-telemetry (Motus Wildlife Tracking System [38]).

We expected that these species would differ in their general departure behaviour according to their migration strategy and associated time constraints. Hence, the long-distance migrant was expected to generally show shorter stopovers and, thus, a higher probability of leaving the stopover site each night (departure probability) as well as generally earlier departures within the night as compared to the medium-distance migrants. Further, we expected birds migrating late in the season, carrying large fuel loads and experiencing weather conditions favourable for migratory flights (e.g. tailwinds, clear skies, high atmospheric pressure), or unfavourable for an extended stopover (e.g. low air temperature) to show higher departure probability and earlier departures within the night than those migrating early in the season, carrying small fuel loads and experiencing opposing weather conditions. The particular effects of different weather variables on birds' departure decisions were expected to be similar 

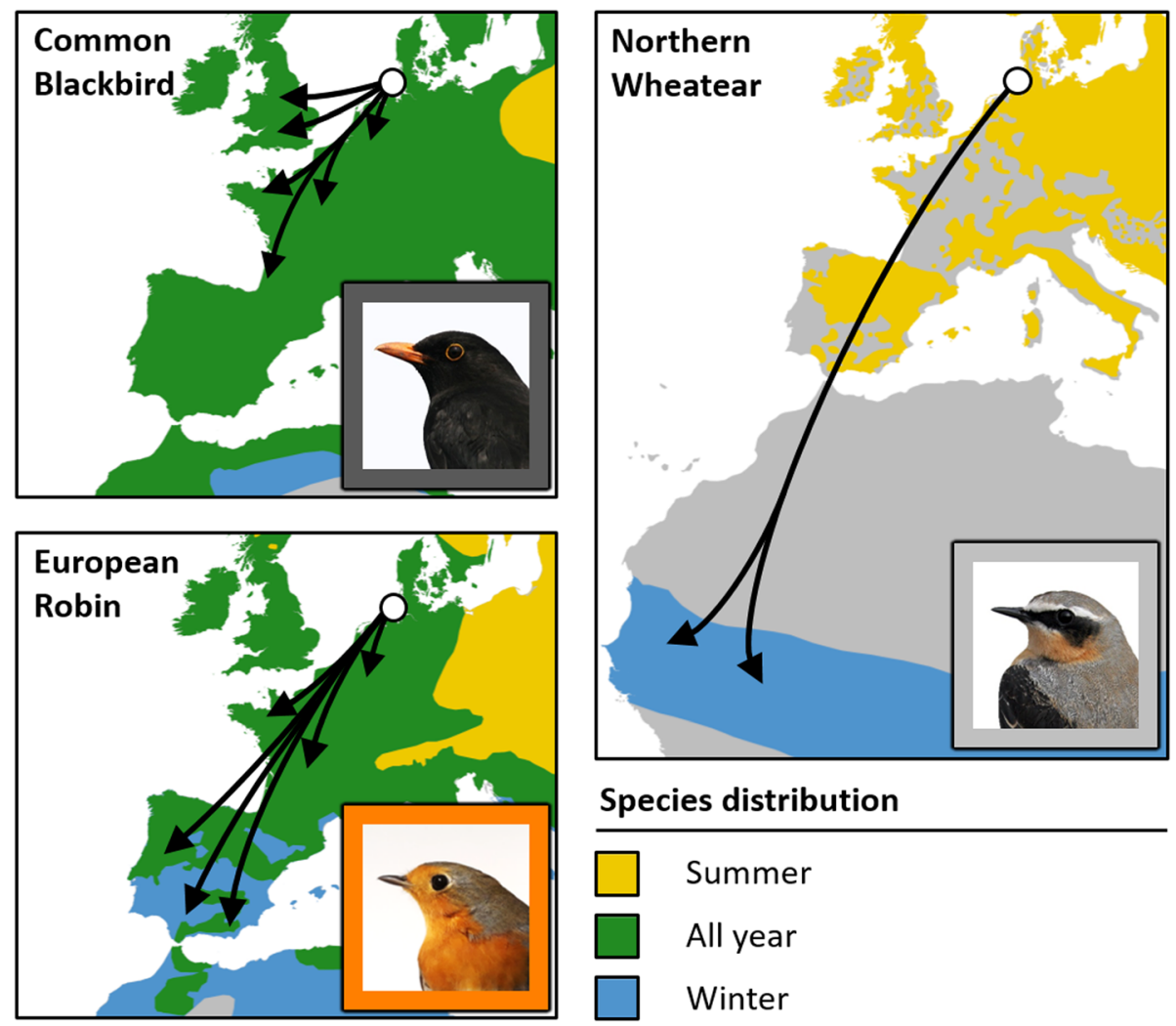

Fig. 1 Hypothetical onward migration routes of Common Blackbirds, European Robins (both medium-distance migrants) and Northern Wheatears (long-distance migrants) departing from Helgoland (white dot) during autumn. Arrows figure simplified hypothetical migration routes towards the species-specific wintering grounds as derived from ring recoveries of birds ringed on Helgoland (Common Blackbirds and European Robins [35]) or estimated wintering locations from light-level geolocation data of European breeding birds (Norther Wheatear [36]). Maps represent an orthographic projection with Helgoland as the projection centre. Species distribution data were provided by BirdLife International [37]

in direction among the species, as the decisionmaking processes should follow the same general principles independent of the migration strategy. Due to differences in the time constraints associated with the respective migration strategy, however, we expected these effects to differ in magnitude. Hence, departure decisions of the long-distance migrants should be less affected by weather conditions than those of the medium-distance migrants, as an increased selectivity for favourable weather probably prolongs the time spent at stopover and, thus, reduces the speed of migration.

\section{Methods}

\section{Study site and study species}

This study was conducted on Helgoland $\left(54^{\circ} 11^{\prime} \mathrm{N}\right.$, $07^{\circ} 53^{\prime} \mathrm{E}$ ), a small island in the North Sea, approx. 50 $\mathrm{km}$ off the German coastline. Many birds stop on Helgoland when crossing the North Sea during migration and use the island for resting and fuelling [35, 39]. We used spring traps baited with mealworms (Tenebrio molitor) to catch migrating Wheatears $(n=$
97) during August to October in 2015 and 2016. Migrating Robins $(n=54)$ and Blackbirds $(n=71)$ were caught with Helgoland traps during September to October 2017 and October to November 2016, respectively. Differences in catching methods and periods are justified by the species-specific differences in habitat use and autumn phenology on Helgoland [35]. Due to the very small size of the island $\left(\mathrm{ca} .1 \mathrm{~km}^{2}\right)$, we assume that the vast majority of birds was caught early during stopover (probably on the day of their arrival), independent of the catching method. Following capture, birds were aged based on plumage characteristics and/or the colouration of the upper mandible depending on the species [40]. We measured wing length (maximum chord [40];) to the nearest $0.5 \mathrm{~mm}$ and body mass to the nearest $0.1 \mathrm{~g}$.

\section{Radio tracking}

Birds were fitted with uniquely coded radio-transmitters (NTQB-1 Avian Nano Tag; weight: $0.29 \mathrm{~g}$; burst interval: 2-4 s; Lotek Wireless Inc., Newmarket, ON, Canada) using leg-loop harnesses adjusted to body size [41]. Mass 
of radio-transmitters including harness (ca. $0.34 \mathrm{~g}$ ) did not exceed 2\% (Wheatears; min. Mass: $18.5 \mathrm{~g}$ ), 2.6\% (Robins; min. Mass: $14.4 \mathrm{~g}$ ) or $0.5 \%$ (Blackbirds; min. Mass: $83.4 \mathrm{~g}$ ) of the bird's body mass, respectively. We used an automated digital radio-telemetry system consisting of four SensorGnome receivers (www.sensorgnome.org) located at three sites on Helgoland and equipped with a total of 12 radially aligned Yagi antennas ([20]; see Additional file 1). This radio-telemetry system continuously recorded radio signals during the study periods to determine the timing of individual departure events.

Departures as detected by this system are generally characterized by a rapid increase in signal strength detected from all/most antennas (bird is setting off the ground), followed by a decline in signal strength from a decreasing number of antennas until the loss of signal (bird is leaving the site towards a specific direction; see Additional file 1). All tracking data were inspected visually. If the specific departure pattern described above was missing, we did not ascertain departure timing. This was the case in 16 of the 97 Wheatears, 23 of the 54 Robins and 17 of the 71 Blackbirds radio-tagged for this study. Since we could not exclude that these birds were caught by a predator during stopover or that their radio-transmitters dropped or stopped transmitting (technical failure, battery life), they were omitted from all analyses. The bird's nocturnal departure timing was defined as the time of highest signal strength during each departure event (see Additional file 1, Figure S1). Based on this timing we calculated the respective temporal difference between initial capture and departure (minimum stopover duration in days), the binary departure decisions of each bird for each day/night they stayed on Helgoland (staying vs. departing), as well as the bird's nocturnal departure timing in relation to night length (proportion of night at departure). For the latter, a representation as proportion of night was necessary to compare the three species, which pass the study site during different periods in autumn and, thus, experience different night durations and sunset/sunrise times. In order to estimate the bird's departure direction, we calculated a weighted circular mean of the directions the receiving antennas were aligned to (see Additional file 1 for details).

\section{Fuel load}

In songbirds, energy stores used to fuel migratory flight primarily consist of accumulated fat and are commonly referred to as fuel loads. We assessed birds' fuel loads at capture following the approach of Schmaljohann \& Naef-Daenzer, 2011 [42]. Based on the individual body mass at capture and the estimated size-specific lean body mass we calculated each bird's fuel load as follows:

$$
\text { fuel load }_{\mathrm{i}}=\frac{\text { body mass }}{\mathrm{i}-\text { lean body mass }} \mathrm{i}
$$

We used wing length $[\mathrm{mm}]$ to estimate birds' sizespecific lean body mass [g], by means of species-specific linear regressions. Regarding Wheatears, we used results of the original regression by Schmaljohann \& NaefDaenzer, 2011 [42] that included 220 individuals with a fat score of $0-1$ and a muscle score of $1[41,42]$ caught on Helgoland in the years 1998-2002 and 2008:

$$
\begin{aligned}
& \text { Northern Wheatear : lean body mass } \\
& \qquad=0.29 \text { gmm }^{-1} * \text { wing length }_{\mathrm{i}}-6.85 \mathrm{~g}
\end{aligned}
$$

$\left(n=220, \mathrm{~F}=95.07, \mathrm{R}^{2}=0.30, p<0.0001\right)$.

To estimate lean body mass of Robins and Blackbirds we considered "lean" individuals (fat score $=0$, muscle score $=1-2$ [43, 44];) caught on Helgoland between 2010 and 2017 yielding the following equations:

$$
\begin{aligned}
& \text { European Robin : lean body } \text { mass }_{\mathrm{i}} \\
& \qquad=0.21 \text { gmm }^{-1} * \text { wing } \text { length }_{\mathrm{i}}-0.42 \mathrm{~g}
\end{aligned}
$$

$$
\begin{aligned}
& \left(n=151, \mathrm{~F}=31.42, \mathrm{R}^{2}=0.17, p<0.0001\right) \\
& \text { Common Blackbird : lean body mass } \mathrm{i}_{\mathrm{i}} \\
& =0.76 \mathrm{gmm}^{-1} * \text { wing length } \mathrm{i}_{\mathrm{i}}-12.08 \mathrm{~g}
\end{aligned}
$$

$$
\left(n=193, \mathrm{~F}=28.53, \mathrm{R}^{2}=0.13, p<0.0001\right)
$$

\section{Weather data}

We used NCEP reanalysis data provided by the National Oceanic and Atmospheric Administration (NOAA; Boulder, CO, USA; http://www.cdc.noaa.gov/cdc/data.ncep.reanalysis. derived.html; [45]) to estimate wind conditions individual birds experienced during their stopover on Helgoland, and at the time of their departure (see Additional file 1 for details). Based on these wind conditions we calculated the tailwind assistance $[\mathrm{m} / \mathrm{s}]$ towards the species-specific mean departure direction (Wheatears: 176 ${ }^{\circ}$; Robins: $138^{\circ}$; Blackbirds: $181^{\circ}$; see Additional file 1 for details) for each bird using the $\mathrm{EQ}^{\text {Tailwind }}[46]$ as follows:

\section{tailwind assistance}

$=$ windspeed $_{\mathrm{i}} * \cos \left(\right.$ wind direction $_{\mathrm{i}}-$ mean departure direction $)$.

Additionally, we calculated the crosswind [absolute values in $\mathrm{m} / \mathrm{s}$ ] each bird experienced perpendicular to 
the species-specific mean departure direction (see above).

Other meteorological data were obtained from an automated weather station on Helgoland operated by the German Meteorological Office (DWD; ftp://ftp-cdc.dwd. $\mathrm{de} /$ pub/CDC/observations_germany/climate/hourly/). We used these measurements to assign atmospheric pressure [mbar], air temperature $\left[{ }^{\circ} \mathrm{C}\right]$, and cloud cover $[\mathrm{x} / 8]$ at both time of sunset for each day a bird stayed on Helgoland and individual nocturnal departure time. As these data include hourly measurements, we assigned the last measurement before either sunset and/or departure. Further, we calculated change in atmospheric pressure and air temperature as the difference between the last measurement prior to either sunset or departure and the respective measurement $24 \mathrm{~h}$ before (see Additional file 1 for details on weather variables).

\section{Statistical analyses}

All statistical analyses were conducted using the software $\mathrm{R}$ version 3.5.2 [47]. All continuous explanatory variables were scaled (z-transformed) on species level prior to modelling (for the original variation in these variables see Additional file 1: Table S1). We did not detect multicollinearity among the continuous explanatory variables (for all variance inflation factor $<1.76$ [48]). In all modelling approaches with two or more explanatory variables included in the initial model, we conducted an automated model selection using the "dredge" function implemented in the R-package "MuMIn" [49]. Subsequent model averaging was performed for all models with a $\triangle \mathrm{AICc}<2[50]$. We used the "model.avg" function implemented in the R-package "MuMIn". We provide average estimates and corresponding 95\% confidence intervals for all explanatory variables included in the selected models with a $\triangle \mathrm{AICc}<2$. If only one model met the selection criterion, we performed no averaging but provide estimates and $95 \%$ confidence intervals of this model. Visual inspection of standard diagnostic plots did not show any serious deviation from model assumptions in either of the models.

All modelling approaches described below were focused on assessing species-specific differences in the birds' night-to-night and within-night departure decisions. In addition, we followed parallel modelling approaches focussing on strategy-specific differences in these departure decisions, with Wheatears representing the long-distance migration strategy, and Robins and Blackbirds together representing the medium-distance migration strategy (see Additional file 1).

\section{Night-to-night departure decisions}

We analysed whether the minimum stopover duration of Robins and Blackbirds differed from those of Wheatears using a Poisson regression model (generalised linear model) with species (categorical: three levels: Wheatear, Robin and Blackbird) as explanatory variable.

The effects of fuel load and weather variables on departure probability were analysed using two different modelling approaches. This was necessary, because all fuel load estimates were based on the birds' body masses at capture and get less reliable with each day they spent at the study site. The modelling approach involving data on fuel load was, therefore, restricted to the departure probability during the first night following capture. Both modelling approaches are detailed below:

1. We assessed the effect of fuel load on departure probability during the first night following capture by fitting binary logistic regression models. The initial model included fuel load (continuous), species, day of year (1 January $=1$; continuous), and the two-way interaction between fuel load and species as explanatory variables. Variables included in the selected models are detailed in Additional file 1: Table S2.

2. We assessed the effect of weather variables on nightto-night departure probability using time-dependent Cox proportional hazards models implemented in the "survival" package [51]. Cox proportional hazards models describe the probability of an event (here 'departure') occurring over time as a function of a baseline probability (hazard), which can be modified by a set of fixed or time-varying explanatory variables [52]. In contrast to others, these models provide the opportunity to include information about weather conditions birds experienced on nights they decided to depart and not to depart, which provides a thorough insight into factors shaping night-to-night departure decisions [26]. We estimated the departure probability as a function of species (fixed variable), day of year (time-varying variable), and a set of weather variables (time-varying variables). Weather variables included in the initial model were tailwind assistance (continuous), crosswind (continuous), cloud cover (proportional), atmospheric pressure (continuous), change in atmospheric pressure ( $\Delta$ atmospheric pressure; continuous), air temperature (continuous), and change in air temperature ( $\Delta$ air temperature; continuous). Additionally, the initial model included the two-way interactions between species and each of the different weather variables. Variables included in the selected models are detailed in Additional file 1: Table S3.

\section{Within-night departure decisions}

The effects of fuel load and weather variables on birds' nocturnal departure timing were analysed in two 
different modelling approaches. The modelling approach involving data on fuel load was restricted to the nocturnal departure timing during the first night following capture for the same reason as described above. Both modelling approaches are detailed below:

1. We assessed the effect of fuel load on nocturnal departure timing (proportion of night at departure) of birds that left Helgoland during the first night following capture by fitting beta regression models using the "betareg" function implemented in the "betareg" package [53]. The initial model included fuel load, species, day of year, and the two-way interaction between fuel load and species as explanatory variables. Only the model including fuel load and species as explanatory variables met the criterion of our selection mentioned above.

2. We assessed the effects of weather variables on nocturnal departure timing (proportion of night at departure) by fitting beta regression models, which included birds leaving Helgoland during the first or any other night following capture. The initial model included species, day of year, tailwind assistance, crosswind, cloud cover, atmospheric pressure, $\Delta$ atmospheric pressure, air temperature, $\Delta$ air temperature, and the two-way interactions between species and each of the different weather variables. Variables included in the selected models are detailed in Additional file 1: Table S4.

\section{Results}

\section{Night-to-night departure decisions}

The three species differed significantly in their minimum stopover duration on Helgoland during autumn (Poisson regression model: Intercept: 0.75 (SE 0.08), $P<0.001$; Robin: 0.81 (SE 0.11), $P<0.001$; Blackbird: 1.07 (SE 0.1), $P<0.001 ; n=160$ ). Robins (median $=3$ days; range $=1-$ 15 days; $n=31$ ) and Blackbirds (median $=5$ days; range $=$ $1-20$ days; $n=54$ ) were found to stay significantly longer than Wheatears (median $=1$ day; range $=1-10$ days; $n=75$; Fig. 2).

Departure probability during the first night was positively correlated with fuel load in all species (Table 1, Fig. 3) and significantly higher in Wheatears (44 individuals, 58.7\%) than in the two medium-distance migrants (Robins: 11 individuals, 35.5\%; Blackbirds: 8 individuals, 14.8\%; Table 1).

Considering the entire stopover period of the birds revealed a similar pattern, with Robins and Blackbirds showing a significantly lower night-to-night departure probability than Wheatears, confirming the results from the Poisson model (Table 2; Fig. 4). Day of year had a positive effect and cloud cover had a negative effect on the night-to-night departure probability in all species (Table 2). The significant two-way interaction between species and tailwind assistance indicated that the nightto-night departure probability of Robins and Blackbirds, but not Wheatears, was affected by tailwind assistance, with higher departure probability under tailwind than under headwind conditions (Table 2; Fig. 5). Crosswind had a negative effect on the night-to-night departure probability in all species (Table 2). The significant twoway interaction between species and $\Delta$ atmospheric pressure indicated that Robins, but not Wheatears and Blackbirds, had a lower departure probability when the atmospheric pressure increased compared to the day before (Table 2). The significant two-way interaction between species and air temperature indicated that departure probability of Blackbirds, but not Wheatears and Robins, was affected by air temperatures experienced during stopover. Blackbirds showed a higher departure probability under colder conditions (Table 2).

\section{Within-night departure decisions}

Nocturnal departure timing, measured as the proportion of night at departure, differed significantly between the species. Robins (median $=0.26$; range $=$ $0.10-0.71 ; n=31$ ) and Blackbirds (median $=0.30$; range $=0.01-0.96 ; n=54)$ were found to depart significantly later within the night than Wheatears (median $=0.21$; range $=0.01-0.83 ; n=75 ;$ Tables 3 and 4 ; Fig. 6 and Additional file 1: Figure S2). Variation in nocturnal departure timing differed significantly between Wheatears and Blackbirds (Fligner-Killeen Test: median $\left.X^{2}=11.62 ; \mathrm{df}=1 ; P<0.001\right)$, with more variation in the Blackbirds, but not between Wheatears and Robins (Fligner-Killeen Test: median $X^{2}=1.96$; $\mathrm{df}=1 ; P=0.16)$. Fuel load had a significant negative effect on nocturnal departure timing during the first night, with relatively large fuel loads yielding early departures in all species (Table 3, Fig. 7a). Further, nocturnal departure timing was positively affected by cloud cover and negatively affected by tailwind assistance (Table 4, Fig. 7b and c). Birds that experienced clear skies and tailwinds departed in general earlier within the night than birds that experienced overcast skies and headwinds (Table 4, Fig. 7b and c).

\section{Discussion}

This study revealed longer stopovers in two mediumdistance migrants (Robin and Blackbird) than in a longdistance migrant (Wheatear) during autumn migration (Fig. 2). Day of year, fuel load, cloud cover and crosswind had consistent effects on night-to-night departure decisions and the resulting departure probabilities in all three species (Tables 1 and 2, Fig. 3). Other parameters, 


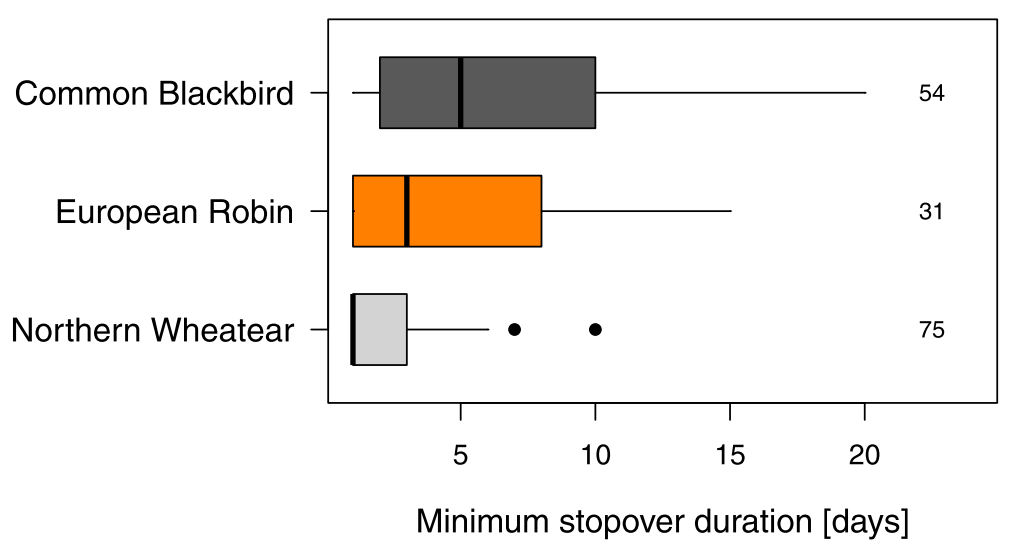

Fig. 2 Variation in minimum stopover duration as observed in Northern Wheatears, European Robins and Common Blackbirds during autumn. Box plots show the 5th, 25th, 50th, 75th and 95th percentile as well as outliers (dots). Sample sizes are 75 (Northern Wheatear), 31 (European Robin) and 54 (Common Blackbird)

like tailwind assistance, change in atmospheric pressure and air temperature, however, had effects on night-to-night departure decisions in both or one of the medium-distance migrants only (Table 2, Fig. 5). In contrast to night-to-night departure decisions, tailwind assistance affected within-night departure decisions and the resulting nocturnal departure timing in all three species in a similar way. Further, there was a consistent effect of fuel load and cloud cover on nocturnal departure timing (Tables 3 and 4). Nocturnal departure timing, however, generally differed between the long-distance migrant and the two mediumdistance migrants, with the former setting off earlier within the night (Tables 3 and 4, Fig. 6). Based on these results we propose that group-specific differences in speed of migration between long- and medium-distance migrants $[1,33,34]$ may be explained by group-specific differences in the night-tonight and within-night departure decision-making process. These differences, in turn, can partly be attributed to a differential selectivity for favourable

Table 1 Effects of fuel load and day of year on departure probability during the first night following capture in Northern Wheatears, European Robins and Common Blackbirds

\begin{tabular}{llll}
\hline Parameter & Estimate \pm SE & $95 \% \mathrm{Cl}$ & $p$ \\
\hline Intercept & $0.395 \pm 0.254$ & $-0.108 / 0.897$ & 0.124 \\
Species (European Robin) & $-1.142 \pm 0.486$ & $0.303 / 1.227$ & $\mathbf{0 . 0 2 0}$ \\
Species (Common Blackbird) & $-2.399 \pm 0.496$ & $0.455 / 1.486$ & $<\mathbf{0 . 0 0 1}$ \\
Fuel load & $0.890 \pm 0.215$ & $-0.494 /-0.072$ & $<\mathbf{0 . 0 0 1}$ \\
Day of year & $-0.257 \pm 0.196$ & $-0.643 / 0.130$ & 0.193
\end{tabular}

Average model estimates, adjusted standard errors (SE), 95\% confidence intervals $(\mathrm{Cl})$ and associated $p$-values of parameters included in the candidate models in Additional file 1: Table S2 are shown. $P$-values $<0.05$ are given in bold font. Reference category for species is Northern Wheatear weather conditions at departure between these two groups.

\section{General differences between species and effect of time within the season}

Variation in total stopover duration and, to a lesser extent, variation in nocturnal departure timing, generally affect variation in the overall speed of migration $[5-7,10,54]$. Songbirds' stopover departure decisions, thus, should conform to the time constraints associated with the respective species- or populationspecific migration strategy. Here we show that stopover departure decisions generally differed between the three investigated songbird species in accordance with their different migration strategies. The behaviour of the long-distance migrant, which showed shortest stopovers, highest departure probabilities and performed earliest departures within the night (Figs. 2, 4 and 6), supports the time-minimising (or speedmaximising) strategy as proposed by optimal bird migration theory $[1,32]$. The two medium-distance migrants, in contrast, showed relatively longer stopovers, lower departure probabilities and later departures within the night suggesting a generally slower pace during migration. Besides these differences, there was a consistent effect of day of year on night-tonight departure decisions, with higher departure probabilities and shorter stopovers towards the end of the respective migration season in all three species. This result is in line with previous studies (e.g. [21]). It can be generally assumed that birds migrating late in the season face increased time constraints as compared to their conspecifics migrating early. Migratory songbirds, thus, may generally adjust their strategy towards minimising the time spent at stopover towards the end of the season [55]. This would require 


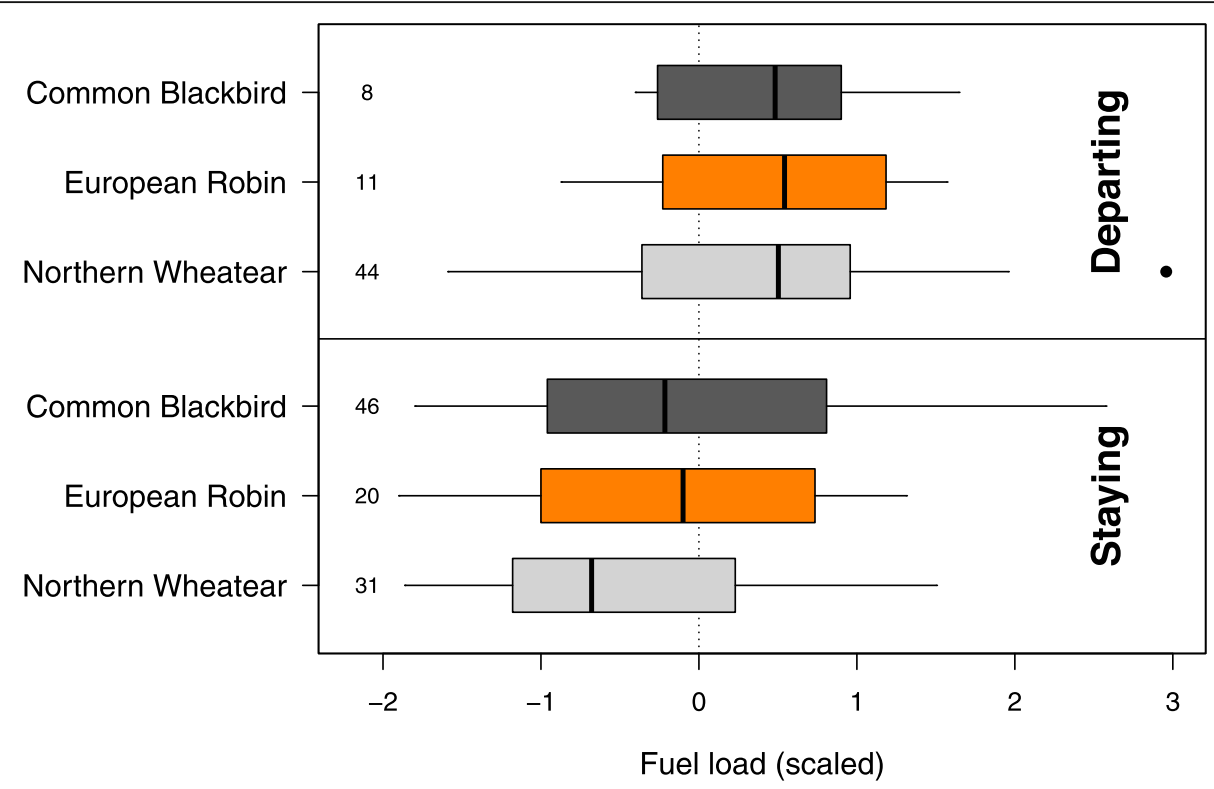

Fig. 3 Fuel load of Northern Wheatears, European Robins and Common Blackbirds that departed the first night following capture (Departing) or that stayed longer at the stopover site (Staying). Box plots show the 5th, 25th, 50th, 75th and 95th percentile as well as outliers (dots). Numbers on the left side of boxes represent sample sizes. Please see Additional file 1: Table S1 for original variation in fuel load

behavioural adjustments at the respective stopover sites, which are likely to come with higher costs for energy and safety in the sense of optimal migration theory $[1,32]$.

\section{Effects of weather conditions (extrinsic factors)}

Our results suggest that differences in night-to-night departure decisions between the one long- and two medium-distance migrant species are at least partly explained by a differential response to extrinsic factors like wind, change in atmospheric pressure and air temperature.

Wind is generally considered as a major determinant of birds' migratory behaviour because it influences the current local flight conditions and associated energetic costs of transport and provides information about flight

Table 2 Effects of weather variables and day of year on night-to-night departure probability in Northern Wheatears, European Robins and Common Blackbirds

\begin{tabular}{|c|c|c|c|}
\hline Parameter & Estimate \pm SE & $95 \% \mathrm{Cl}$ & $p$ \\
\hline Species (European Robin) & $-1.112 \pm 0.240$ & $-1.581 /-0.642$ & $<0.001$ \\
\hline Species (Common Blackbird) & $-1.531 \pm 0.243$ & $-2.008 /-1.054$ & $<0.001$ \\
\hline Cloud cover & $-0.171 \pm 0.078$ & $-0.324 /-0.017$ & 0.029 \\
\hline Tailwind assistance & $0.100 \pm 0.134$ & $-0.173 / 0.351$ & 0.506 \\
\hline Crosswind & $-0.324 \pm 0.105$ & $-0.530 /-0.120$ & 0.002 \\
\hline Atmospheric pressure & $0.166 \pm 0.100$ & $-0.030 / 0.362$ & 0.098 \\
\hline$\Delta$ atmospheric pressure & $0.138 \pm 0.126$ & $-0.108 / 0.384$ & 0.273 \\
\hline Air temperature & $0.340 \pm 0.173$ & $0.000 / 0.680$ & 0.050 \\
\hline Day of year & $0.330 \pm 0.108$ & $0.118 / 0.542$ & 0.002 \\
\hline Species (European Robin) $x$ tailwind assistance & $0.644 \pm 0.266$ & $0.123 / 1.165$ & 0.015 \\
\hline Species (Common Blackbird) $\times$ tailwind assistance & $0.550 \pm 0.215$ & $0.128 / 0.972$ & 0.011 \\
\hline Species (European Robin) $\times \Delta$ atmospheric pressure & $-0.617 \pm 0.269$ & $-1.144 /-0.089$ & 0.022 \\
\hline Species (Common Blackbird) $\times \Delta$ atmospheric pressure & $-0.013 \pm 0.181$ & $-0.369 / 0.343$ & 0.943 \\
\hline Species (European Robin) x air temperature & $-0.088 \pm 0.293$ & $-0.663 / 0.487$ & 0.765 \\
\hline Species (Common Blackbird) $x$ air temperature & $-0628 \pm 0.216$ & $-1.051 /-0.205$ & 0.004 \\
\hline
\end{tabular}

Average model estimates, adjusted standard errors (SE), 95\% confidence intervals (Cls) and associated $p$-values of parameters included in the candidate models in Additional file 1: Table S3 are shown. $P$-values $<0.05$ are given in bold font. Reference category for species is Northern Wheatear 


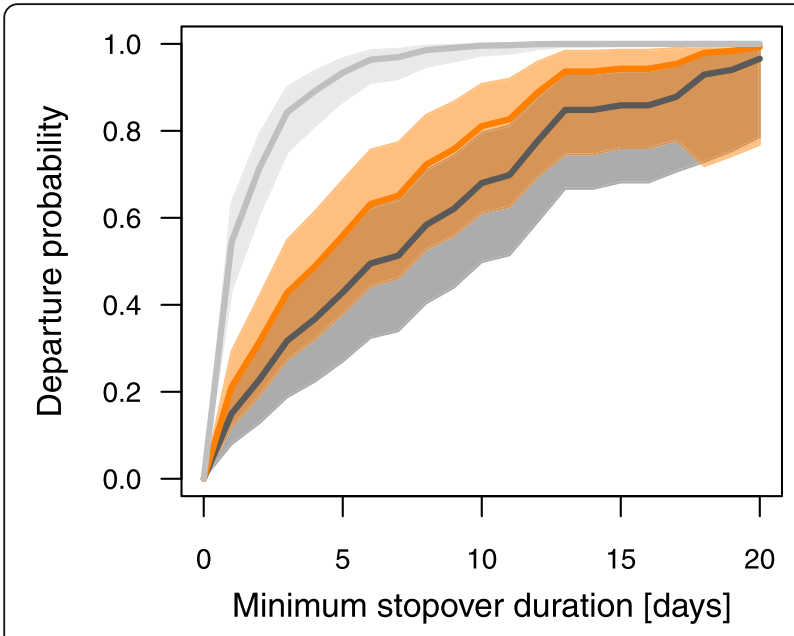

Fig. 4 Night-to-night departure probability in Northern Wheatears (light grey), European Robins (orange) and Common Blackbirds (dark grey) predicted by a time-dependent Cox proportional hazards model. Species-specific predictions (lines) and associated 95\% confidence intervals (shaded areas) are given. To illustrate the species-specific differences in the departure probability we used the candidate model with the best fit (Additional file 1: Table S3).

Predictions were made with the remaining variables included in the model set to their mean

conditions to be expected in the near future [56, 57]. In this study, we found that night-to-night departure decisions of the medium-distance migrants, Robins and Blackbirds, were affected by tailwind assistance, with higher departure probabilities under tailwind than under headwind conditions. This was not the case in the
Wheatears (Fig. 5), which again is in line with the timeminimising strategy suggested for long-distance migrants (e.g. [1]). Crosswind, in contrast, affected the night-tonight departure decisions of all three species alike and generally lowered birds' departure probabilities. We propose that during stopover migrants may generally face a trade-off between waiting for favourable tailwind conditions to minimize their energetic costs of transport and resuming migration as soon as they are physiologically capable to minimize stopover duration and, thus, increase their overall speed of migration. The individual bird's assessment of such a trade-off and the resulting night-to-night departure decision could be driven by its general migration strategy and the associated time constraints. The apparent avoidance of crosswind at departure, however, appears to be strategy-independent based on the current data. Such a general response to crosswind in night-to-night departure decisions would help birds to minimise lateral drift, which, if unintended, could be fatal during the sea crossing following a departure from Helgoland. Within-night departure decisions were found to be affected by tailwind assistance in all three species alike. This suggests that the observed effect of tailwind conditions on within-night departure decisions may represent a more general mechanism, which seems independent of the respective migration strategy. In fact, once a bird has decided to depart on a given night, it will benefit from relatively early departures under favourable wind conditions. Benefits include both an increase in the potential nocturnal flight duration and flight distance [10] and a decrease in the associated energetic costs of transport.
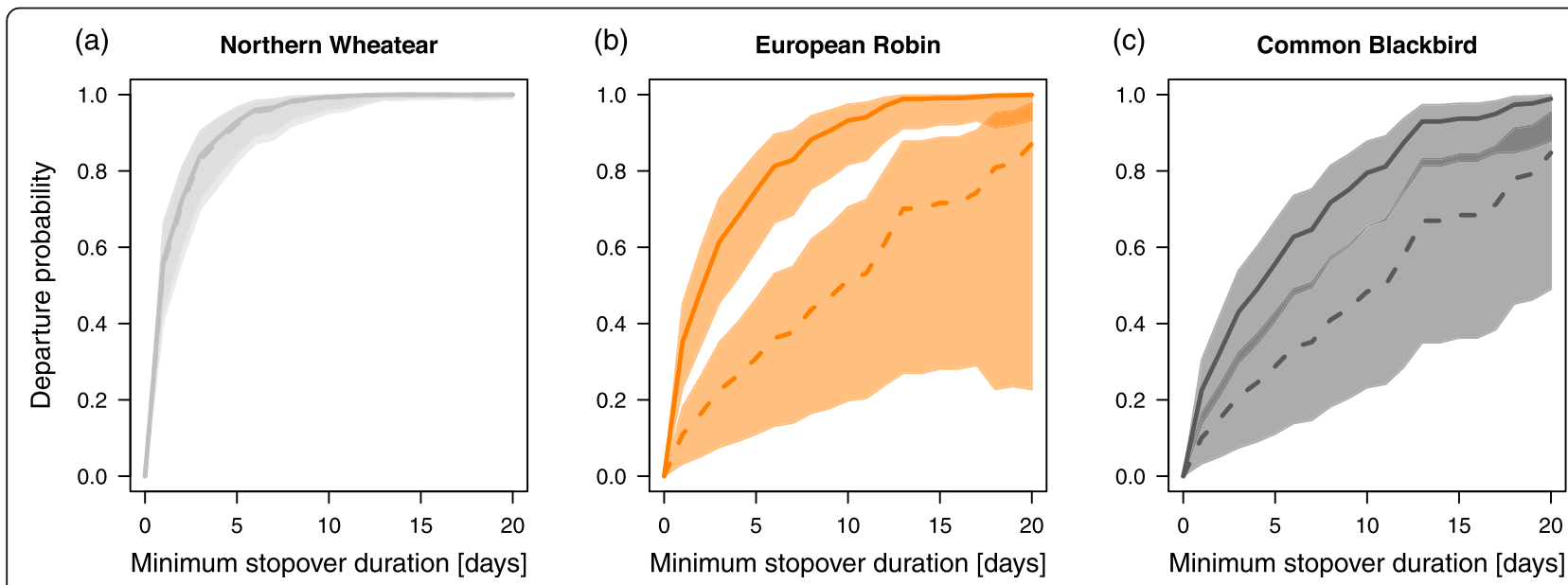

Fig. 5 Night-to-night departure probability under different tailwind/headwind conditions in Northern Wheatears, European Robins and Common Blackbirds predicted by a time-dependent Cox proportional hazards model. Species-specific predictions (lines) and associated $95 \%$ confidence intervals (shaded areas) are given for the 25th percentile (broken line; light headwind) and 75th percentile (solid line; light tailwind) of the scaled tailwind assistance birds experienced at sunset. Details on the variation in tailwind assistance are given in Additional file 1: Table S1. To illustrate the effect of tailwind assistance on departure probability we used the candidate model with the best fit (Additional file 1: Table S3). Predictions were made with the remaining variables included in the model set to their mean 
Table 3 Effect of fuel load on nocturnal departure timing (proportion of night at departure) during the first night following capture in Northern Wheatears, European Robins and Common Blackbirds

\begin{tabular}{llll}
\hline Parameter & Estimate \pm SE & $95 \% \mathrm{Cl}$ & $p$ \\
\hline Intercept & $-1.284 \pm 0.124$ & $-1.527 /-1.040$ & $<\mathbf{0 . 0 0 1}$ \\
Species (European Robin) & $0.765 \pm 0.236$ & $0.303 / 1.227$ & $\mathbf{0 . 0 0 1}$ \\
Species (Common Blackbird) & $0.971 \pm 0.263$ & $0.455 / 1.486$ & $<\mathbf{0 . 0 0 1}$ \\
Fuel load & $-0.283 \pm 0.108$ & $-0.494 /-0.072$ & $\mathbf{0 . 0 0 9}$
\end{tabular}

Estimates, standard errors (SE), 95\% confidence intervals (Cls) and associated $p$-values of all parameters included in the final model are shown. $P$-values $<$ 0.05 are given in bold font. Reference category for species is Northern Wheatear

Changes in atmospheric pressure were found to affect night-to-night departure decisions in one of the two medium-distance migrant species. Robins were found to be less likely to depart when atmospheric pressure increased compared to the previous day. This is contrary to the results of previous studies reporting higher departure probabilities in migratory songbirds in response to increases in atmospheric pressure [26, 31, 58]. Birds are assumed to use atmospheric pressure and its changes as cues to predict favourable flight conditions for migration and respond accordingly, with high and/or increasing atmospheric pressure often promoting departure [59-61]. Beyond that, atmospheric pressure may alter the foraging conditions at stopover for insectivorous birds, because it is known to affect the activity patterns of insects [62]. Therefore, an effect of changes in atmospheric pressure on birds' night-to-night departure decisions could potentially be based on associated changes in insect activity and, thus, food availability at stopover.
In fact, it has been demonstrated that a bird's behavioural response to atmospheric pressure can change over the course of its migratory journey [19]. This implies flexible adjustments in the assessment of this cue for the individual stopover departure decision.

Air temperatures also had an effect on night-to-night departure decisions in one of the two medium-distance migrant species. Blackbirds showed a higher departure probability when air temperatures near the surface were relatively low, which is in line with previous studies [4, 19, 23]. It is known that birds can reduce energetic costs associated with thermoregulation by avoiding low air temperatures during stopover [3]. Thus, low air temperatures should promote departure from stopover, especially during autumn migration when warmer conditions can be expected towards the southerly migratory destination. Blackbirds were probably more responsive to air temperatures than the other species, because they experienced, on average, lowest temperatures during stopover (Additional file 1: Table S1). Previous studies demonstrated a similar response of Wheatears to variation in air temperatures [4, 19, 23]. Probably, Wheatears and Robins considered in this study did not experience air temperatures low enough to promote the corresponding behavioural response, i.e., departure from stopover.

Cloud cover, as opposed to the other weather variables considered in this study, was found to have a consistent effect on both night-to-night and within-night departure decisions in all three species. Birds generally had a higher departure probability and departed earlier within the night under clear skies than under overcast conditions, which is in line with the results of other studies

Table 4 Effects of weather variables and day of year on nocturnal departure timing (proportion of night at departure) in Northern Wheatears, European Robins and Common Blackbirds

\begin{tabular}{|c|c|c|c|}
\hline Parameter & Estimate \pm SE & $95 \% \mathrm{Cl}$ & $p$ \\
\hline Intercept & $-1.171 \pm 0.097$ & $-1.361 /-0.981$ & $<0.001$ \\
\hline Species (European Robin) & $0.356 \pm 0.169$ & $0.025 / 0.687$ & 0.035 \\
\hline Species (Common Blackbird) & $0.379 \pm 0.142$ & $0.100 / 0.657$ & 0.008 \\
\hline Cloud cover & $0.238 \pm 0.084$ & $0.072 / 0.403$ & 0.005 \\
\hline Tailwind assistance & $-0.213 \pm 0.090$ & $-0.388 /-0.037$ & 0.020 \\
\hline Crosswind & $-0.042 \pm 0.065$ & $-0.170 / 0.090$ & 0.517 \\
\hline Atmospheric pressure & $-0.052 \pm 0.072$ & $-0.193 / 0.090$ & 0.473 \\
\hline$\Delta$ air temperature & $0.057 \pm 0.068$ & $-0.076 / 0.190$ & 0.400 \\
\hline Day of year & $-0.042 \pm 0.067$ & $-0.174 / 0.089$ & 0.530 \\
\hline Species (European Robin) x cloud cover & $0.218 \pm 0.176$ & $-0.127 / 0.564$ & 0.216 \\
\hline Species (Common Blackbird) x cloud cover & $0.211 \pm 0.145$ & $-0.073 / 0.496$ & 0.146 \\
\hline Species (European Robin) x tailwind assistance & $0.085 \pm 0.171$ & $-0.251 / 0.421$ & 0.620 \\
\hline Species (Common Blackbird) $x$ tailwind assistance & $-0.259 \pm 0.149$ & $-0.551 / 0.032$ & 0.082 \\
\hline
\end{tabular}

Average model estimates, adjusted standard errors (SE), 95\% confidence intervals (Cls) and associated $p$-values of parameters included in the candidate models in Additional file 1: Table S4 are shown. $P$-values $<0.05$ are given in bold font. Reference category for species is Northern Wheatear 


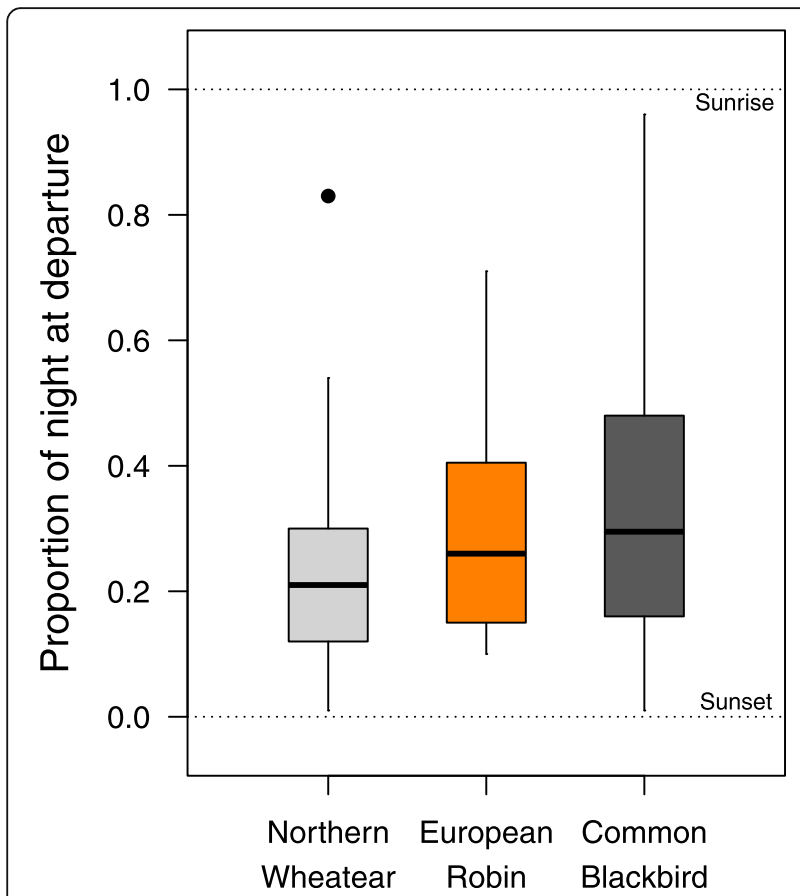

Fig. 6 Variation in nocturnal departure timing as observed in Northern Wheatears, European Robins and Common Blackbirds during autumn. Nocturnal departure timing is expressed as proportion of night at departure. Box plots show the 5th, 25th, 50th, 75th and 95th percentile as well as outliers (dots). Sample sizes are 75 (Northern Wheatear), 31 (European Robin) and 54 (Common Blackbird)
$([26,28,58,63,64]$ but see $[61,65])$. Two mutually nonexclusive causes seem conceivable to explain this general pattern. First, migrants may generally postpone their departures if the conditions for nocturnal orientation are suboptimal, i.e., celestial cues (e.g. stars) required for orientation are not visible (e.g. [21, 26, 28, 58]). Second, overcast conditions are usually associated with an increased probability of precipitation, which in turn represents a hazard during flight [66]. Migrants, thus, should consider the probability of precipitation for their departure decision and respond accordingly. We argue that cloud cover seems to have a general effect on stopover departure decisions irrespective of the migration strategy, because of its consequences for birds' orientation ability and survival probability.

\section{Effect of fuel load (intrinsic factor)}

Fuel is required for locomotion and, thus, limits the potential duration and distance of a bird's migratory flight (e.g. [27]). Therefore, the individual fuel load and its recent changes are considered fundamental cues for birds' stopover departure decisions and the adjustments of migratory behaviour (e.g. [1, 10, 27, 67-69]). Furthermore, fuel loads acquired at stopover carry-over to influence the spatio-temporal progress of migration in songbirds across continents [70]. Our results are in line with most previous studies (reviewed in [10, 27]), with relatively large fuel loads promoting early departures during the first night following capture on both temporal scales, both in the one long-distance and the two mediumdistance migrant species. This suggests that the adjustments of birds' individual stopover departure decisions
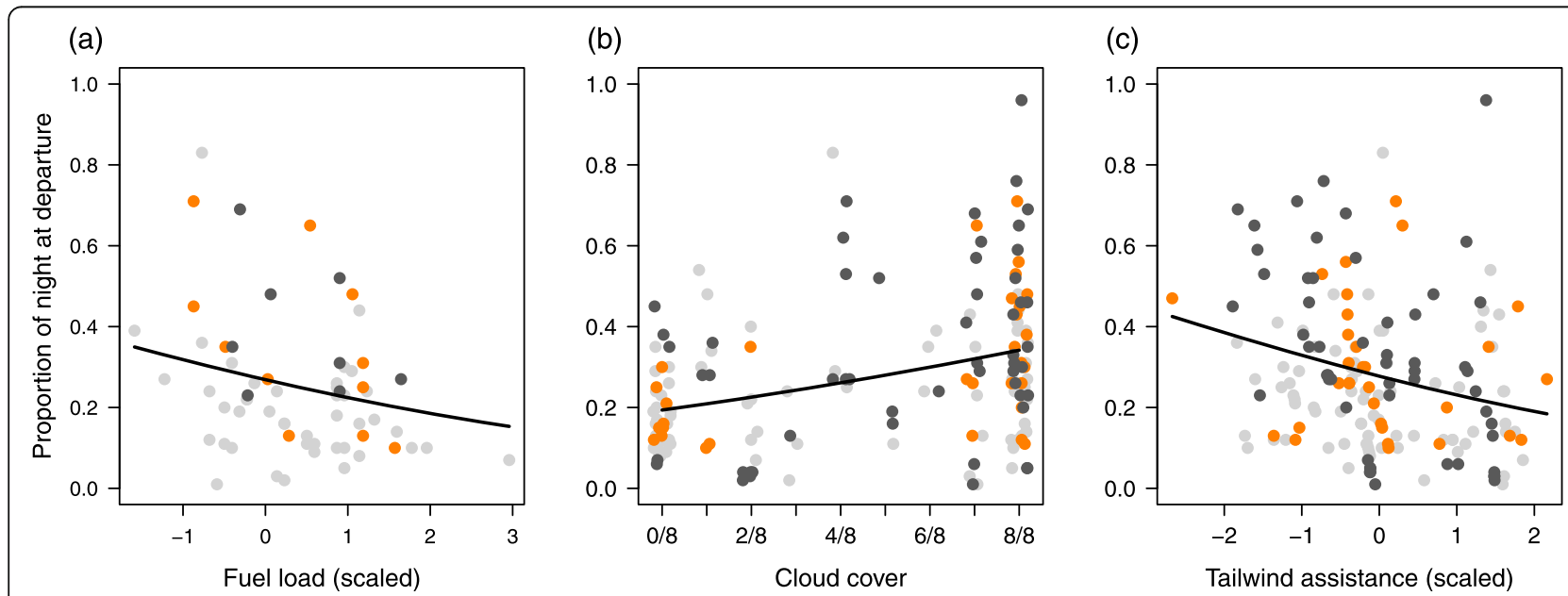

Fig. 7 Effects of (a) fuel load, (b) cloud cover and (c) tailwind assistance on nocturnal departure timing (proportion of night at departure) obtained from two beta regression models (Tables 3 and 4). Shown are the respective model predictions (black lines) and the raw data (dots) for Northern Wheatears (light grey), European Robins (orange) and Common Blackbirds (dark grey). To illustrate the effects of fuel load, cloud cover and tailwind assistance we used the respective candidate models with the best fit (Additional file 1: Table S3). The remaining variables included in the respective model were set to their mean and species was not considered. Please see Additional file 1: Table S1 for original variation in fuel load and tailwind assistance 
with regard to fuel load seem to follow a common principle independent of the species-specific migration strategy and the associated time constraints. Exceptions from this principle are scarce and usually coincide with specific geographical circumstances (e.g. songbirds encountering an ecological barrier, like the sea) potentially masking the direct effect of fuel (e.g. $[20,21])$. Thus, we assume that migratory songbirds generally consider their fuel loads in stopover departure decisions on both temporal scales. Additionally, they integrate a number of other factors (see above) in the decision-making process, which may act as departure cues depending on the specific migration strategy and the respective geographical and ecological context.

\section{Conclusions}

The results of this study are based on radio-telemetry data obtained from migrating songbirds caught at an island stopover site and tracked until their individual departure. Therefore, we have no information on the exact locations of the birds' actual breeding areas and wintering grounds and, hence, their individual migration distances. Further, we lack information on the spatio-temporal progress during preceding stages of their journey. Instead, we are limited to allocating the birds to distinct groups based on the estimated average migration strategies of populations passing our study site (see Fig. 1). Despite these limitations, our results generally support the hypothesis that differences in migration strategies and associated time constraints affect stopover departure decisions of migratory songbirds. We found that in a long-distance migrant, the average stopover duration was shorter and departures occurred, on average, earlier within the night than in two medium-distance migrants. Stopover departure decisions were found to be affected by a set of intrinsic and extrinsic factors, both on the night-to-night and within-night scale. Some factors had consistent effects on stopover departure decisions in all three investigated species. Species, however, differed in the effect of certain extrinsic factors, i.e., weather conditions, on night-to-night departure decisions, with the long-distance migrant species generally being least affected. This may imply a differential selectivity for favourable weather at departure between long- and medium-distance migrants. Based on the current data, we suggest that migratory songbirds adjust their assessment of specific weather conditions as departure cues based on their migration strategy and the associated time constraints. Nonetheless, similar studies on other migrant species and at other stopover sites are required to test the generality of our results and conclusions. Finally, we stress the importance of interpreting data on songbirds' nocturnal migratory behaviour, including stopover departure decisions, in the respective ecological and geographical context of the landscapes and habitats they traverse. Individual behavioural responses to certain intrinsic and extrinsic factors may change along the migration route and over the course of the season $[19,20]$.

\section{Supplementary information}

Supplementary information accompanies this paper at https://doi.org/10. 1186/s40462-020-0193-1.

\section{Additional file 1: Additional methods: Radio tracking and weather data. Figure S1. Radio-telemetry system on Helgoland and example of signals received during the departure of a radio tracked northern wheatear. Figure S2. Variation in nocturnal departure timing as observed in Northern Wheatears, European Robins and Common Blackbirds during autumn. Table S1. Variation in explanatory variables used to explain night-to-night and within-night departure decisions in the three investigated migratory songbird species. Table S2. Comparison of candidate binary logistic regression models to assess the effect of fuel load on birds' departure probability during the first night following capture (night-to-night departure decision). Table S3. Comparison of candidate time-dependent Cox proportional hazards models to assess the effects of weather variables on birds' departure probability (night-to- night departure decision). Table S4. Comparison of candidate beta regression models to assess the effects of weather variables on birds' nocturnal departure timing (proportion of night at departure; within- night departure decision). Strategy-specific differences in birds' night-to- night and within-night departure decisions: Modelling approaches, Results.}

\section{Acknowledgements}

We thank Elmar Ballstaedt, Jonas Buddemeier, Jochen Dierschke, Sven Hessler, Iris Kleudgen, Konstantin Lebus, Clara Leutgeb, and Klaus Müller for excellent support on Helgoland during fieldwork. Birdlife International kindly provided bird distribution data. Linda Tendler helped us handling mapbased data. Nir Sapir, Mariëlle van Toor and an anonymous reviewer provided helpful comments that improved the final manuscript.

\section{Authors' contributions}

FP and HS conceived the study. FP, CE and TK collected the data. FP and BKW analysed the data. FP and HS wrote the manuscript with critical contributions by BKW, CE and TK. All authors gave final approval for publication.

\section{Funding}

This study was financially supported by two Deutsche Forschungsgemeinschaft (DFG) grants, both awarded to HS (SCHM 2647/1-2 and SCHM 2647/3-1) and by a research fund from the Deutsche Ornithologen-Gesellschaft (DO-G) awarded to HS and CE.

Availability of data and materials

We intend to provide all relevant data in the Dryad Digital Repository.

Ethics approval and consent to participate

All procedures were approved by the Ministry for Agriculture, the Environment and Rural Areas, Schleswig-Holstein, Germany (permission numbers: V244-7224.121.9-11 (3-1/14), V244-4829/2017 (33-3/17)).

Consent for publication

"Not applicable".

Competing interests

The authors declare that they have no competing interests. 


\section{Author details}

"Institute of Avian Research "Vogelwarte Helgoland", An der Vogelwarte 21, 26386 Wilhelmshaven, Germany. ${ }^{2}$ School of Natural Sciences, Bangor University, Deiniol Road, Bangor LL57 2UW, UK. ${ }^{3}$ School of Biological Sciences, The University of Queensland, Brisbane, Queensland 4072, Australia. ${ }^{4}$ Institute for Biology und Environmental Sciences, Carl von Ossietzky University of Oldenburg, Carl-von-Ossietzky-Straße, 26129 Oldenburg, Germany.

Received: 18 September 2019 Accepted: 16 January 2020 Published online: 07 February 2020

\section{References}

1. Alerstam T, Lindström Å. Optimal bird migration: the relative importance of time, energy, and safety. In: Gwinner E, editor. Bird migration: physiology and Ecophysiology. Berlin: Springer; 1990. p. 331-51.

2. Hedenström A, Alerstam T. Optimum fuel loads in migratory birds: distinguishing between time and energy minimization. J Theor Biol. 1997; 189:227-34.

3. Wikelski M, Tarlow EM, Raim A, Diehl RH, Larkin RP, Visser GH. Costs of migration in free-flying songbirds. Nature. 2003;423:704.

4. Schmaljohann H, Fox JW, Bairlein F. Phenotypic response to environmental cues, orientation and migration costs in songbirds flying halfway around the world. Anim Behav. 2012:84:623-40.

5. Schmaljohann $\mathrm{H}$, Both $\mathrm{C}$. The limits of modifying migration speed to adjust to climate change. Nat Clim Chang. 2017;7:573-6.

6. Schmaljohann H. Proximate mechanisms affecting seasonal differences in migration speed of avian species. Sci Rep. 2018;8:4106.

7. Nilsson C, Klaassen RHG, Alerstam T. Differences in speed and duration of bird migration between spring and autumn. Am Nat. 2013;181:837-45

8. Dorka V. Das jahres- und tageszeitliche Zugmuster von Kurz- und Langstreckenziehern nach Beobachtungen auf den Alpenpässen Cou/ Bretolet (Wallis). Ornithol Beob. 1966;63:165-223.

9. Alerstam T. Flight by night or day? Optimal daily timing of bird migration. J Theor Biol. 2009;258:530-6.

10. Müller F, Taylor PD, Sjöberg S, Muheim R, Tsvey A, Mackenzie SA, Schmaljohann $\mathrm{H}$. Towards a conceptual framework for explaining variation in nocturnal departure time of songbird migrants. Mov Ecol. 2016;4:24.

11. Liechti F, Bauer S, Dhanjal-Adams KL, Emmenegger T, Zehtindjiev P, Hahn S. Miniaturized multi-sensor loggers provide new insight into year-round flight behaviour of small trans-Sahara avian migrants. Mov Ecol. 2018;6:19.

12. Marra PP, Hobson KA, Holmes RT. Linking winter and summer events in a migratory bird by using stable-carbon isotopes. Science. 1998;282:1884-6.

13. Marra PP, Holmes RT. Consequences of dominance-mediated habitat segregation in American redstarts during the nonbreeding season. Auk. 2001:118:92-104.

14. Smith RJ, Moore FR. Arrival timing and seasonal reproductive performance in a longdistance migratory landbird. Behav Ecol Sociobiol. 2005:5:231-9.

15. Berthold P. Relationships between migratory restlessness and migration distance in six Sylvia species. Ibis. 1973;115:594-9.

16. Gwinner E. Circadian and circannual programmes in avian migration. J Exp Biol. 1996;199:39-48.

17. Gwinner E, Helm B. Circannual and circadian contributions to the timing of avian migration. In: Berthold P, Gwinner E, Sonnenschein E, editors. Avian migration. Berlin: Springer Verlag; 2003. p. 81-95.

18. Maggini I, Bairlein F. Endogenous rhythms of seasonal migratory body mass changes and nocturnal restlessness in different populations of northern wheatear Oenanthe oenanthe. J Biol Rhythm. 2010;25:268-76.

19. Schmaljohann $\mathrm{H}$, Lisovski S, Bairlein F. Flexible reaction norms to environmental variables along the migration route and the significance of stopover duration for total speed of migration in a songbird migrant. Front Zool. 2017;14:17.

20. Müller F, Eikenaar C, Crysler ZJ, Taylor PD, Schmaljohann H. Nocturnal departure timing in songbirds facing distinct migratory challenges. J Anim Ecol. 2018;87:1102-15.

21. Dierschke V, Delingat J. Stopover behaviour and departure decision of northern wheatears, Oenanthe oenanthe, facing different onward non-stop flight distances. Behav Ecol Sociobiol. 2001;50:535-45.

22. Goymann W, Spina F, Ferri A, Fusani L. Body fat influences departure from stopover sites in migratory birds: evidence from whole island telemetry. Biol Lett. 2010;6:478-81.
23. Schmaljohann H, Korner-Nievergelt F, Naef-Daenzer B, Nagel R, Maggini I, Bulte M, Bairlein F. Stopover optimization in a long-distance migrant: the role of fuel load and nocturnal take-off time in Alaskan northern wheatears (Oenanthe oenanthe). Front Zool. 2013;10:26.

24. Smolinsky JA, Diehl RH, Radzio TA, Delaney DK, Moore FR. Factors influencing the movement biology of migrant songbirds confronted with an ecological barrier. Behav Ecol Sociobiol. 2013;67:2041-51.

25. Dossman BC, Mitchell GW, Norris DR, Taylor PD, Guglielmo CG, Matthews SN, Rodewald PG. The effects of wind and fuel stores on stopver departure behavior across a migratory barrier. Behav Ecol. 2015;27:567-74.

26. Woodworth BK, Mitchell GW, Norris DR, Francis CM, Taylor PD. Patterns and correlates of songbird movements at an ecological barrier during autumn migration assessed using landscape- and regional-scale automated radiotelemetry. Ibis. 2015;157:326-39.

27. Schmaljohann $\mathrm{H}$, Eikenaar $\mathrm{C}$. How do energy stores and changes in these affect departure decisions by migratory birds? - a critical view on stopover ecology studies and some future perspectives. J Comp Physiol A. 2017:203:411-29.

28. Sjöberg S, Alerstam T, Åkesson S, Muheim R. (2017) ecological factors influence timing of departures in nocturnally migrating songbirds at Falsterbo, Sweden. Anim Behav. 2017;127:253-69.

29. Nilsson C, Bäckman J, Alerstam T. Seasonal modulation of flight speed among nocturnal passerine migrants: differences between short- and longdistance migrants. Behav Ecol Sociobiol. 2014;68:1799-807.

30. Newton I. Obligate and facultative migration in birds: ecological aspects. J Ornithol. 2013;5153:171-80.

31. Dänhardt J, Lindström Å. Optimal departure decisions of songbirds from an experimental stopover site and the significance of weather. Anim Behav. 2001:62:235-43.

32. Alerstam T. Optimal bird migration revisited. J Ornithol. 2011;152:S5-23.

33. Ellegren $\mathrm{H}$. Speed of migration and migratory flight lengths of passerine birds ringed duringAutumn migration in Sweden. Ornis Scand. 1993;24:220-8.

34. Fransson T. Timing and speed of migration in north and west European populations of Sylvia warblers. J Avian Biol. 1995;26:39-48.

35. Dierschke J, Dierschke V, Hüppop K, Hüppop O, Jachmann KF. Die Vogelwelt der Insel Helgoland. Helgoland: OAG Helgoland; 2011.

36. Schmaljohann $\mathrm{H}$, Meier C, Arlt D, Bairlein F, van Oosten HH, Morbey YE, Åkesson S, Buchmann M, Chernetsov N, Desaever R, et al. Proximate causes of avian protandry differ between subspecies with contrasting migration challenges. Behav Ecol. 2015;27:231-331.

37. BirdLife International and Handbook of the Birds of the World. Bird species distribution maps of the world. Version 6.0. 2016. Available at http:// datazone.birdlife.org/species/requestdis

38. Taylor PD, Crewe TL, Mackenzie SA, Lepage D, Aubry Y, Crysler Z, Finney G, Francis CM, Guglielmo CG, Hamilton DJ, Holberton RL, Loring PH, Mitchell GW, Norris DR, Paquet J, Ronconi RA, Smetzer JR, Smith PA, Welch LJ, Woodworth BK. The Motus wildlife tracking system: a collaborative research network to enhance the understanding of wildlife movement. Avian Conserv Ecol. 2017;12:8.

39. Hüppop O, Hüppop K. Bird migration on Helgoland: the yield from 100 years of research. J Ornithol. 2011;152:S25-40.

40. Svensson L. Identification guide to European passerines. 4th ed. Stockholm: BTO; 1992.

41. Naef-Daenzer B. An allometric function to fit leg-loop harnesses to terrestrial birds. J Avian Biol. 2007;38:404-7.

42. Schmaljohann H, Naef-Daenzer B. Body condition and wind support initiate shift in migratory direction and timing of nocturnal departure in a free flying songbird. J Anim Ecol. 2011;80:1115-22.

43. Kaiser A. A new multi-category classification of subcutaneous fat deposits of songbirds. J Field Ornithol. 1993;64:246-55.

44. Bairlein F. Manual of field methods. European-African songbird migration network. Wilhelmshaven: Institut für Vogelforschung; 1995.

45. Kalnay E, Kanamitsu M, Kistler R, Collins W, Deaven D, Gandin L, Iredell M, Saha S, White G, Woollen J, Zhu Y, Leetmaa A, Reynolds R, Chelliah M, Ebisuzaki W, Higgins W, Janowiak J, Mo KC, Ropelewski C, Wang J, Jenne R, Joseph D. The NCEP/NCAR 40-year reanalysis project. Bull Am Meteorol Soc. 1996;77:437-71.

46. Kemp MU, Shamoun-Baranes J, van Loon EE, McLaren JD, Dokter AM, Bouten W. Quantifying flow-assistance and implications for movement research. J Theor Biol. 2012;308:56-67.

47. R Core Team. R: A language and environment for statistical computing. Vienna, Austria: R Foundation for Statistical Computing. 2018. Retrieved from http://www.r-project.org/ 
48. Zuur AE, Irwin DE, Elphick CS. A protocol for data exploration to avoid common statistical probelms. Methods Ecol Evol. 2010;1:3-14.

49. Barton K. MuMIn: Multi-Model Inference. R package version 1.42.1. 2018. https://CRAN.R-project.org/package=MuMln

50. Burnham KP, Anderson DR. Multimodel interference: understanding AIC and BIC in model selection. Sociol Methods Res. 2004;33:261-304.

51. Therneau T. A Package for Survival Analysis in S. R package version 2.38 2015. https://CRAN.R-project.org/package=survival.

52. Gienapp P, Hemerik L, Visser ME. A new statistical tool to predict phenology under climate change scenarios. Glob Chang Biol. 2005;11:600-6.

53. Cribari-Neto F, Zeileis A. Beta Regression in R. J Stat Softw. 2010;34:1-24.

54. Tøttrup AP, Klaassen RHG, Kristensen MW, Strandberg R, Vardanis $Y$, Lindström Å, Rahbek C, Alerstam T, Thorup K. Drought in Africa caused delayed arrival of European songbirds. Science. 2012;338:1307.

55. Eikenaar C, Fritzsch A, Kämpfer S, Schmaljohann H. Migratory restlessness increases and refuelling rate decreases over the spring migration season in northern wheatears. Anim Behav. 2016;112:75-81.

56. Liechti F. Birds: blowin' by the wind? J Ornithol. 2006;147:202-11.

57. Shamoun-Baranes J, Liechti F, Vansteelant WMG. Atmospheric conditions create freeways, detours and tailbacks for migrating birds. J Comp Physiol A. 2017;203:509-29.

58. Åkesson S, Walinder G, Karlsson L, Ehnbom S. Reed warbler orientation: initiation of nocturnal migratory flights in relation to visibility of celestial cues at dusk. Anim Behav. 2001;61:181-9.

59. Richardson WJ. Nocturnal landbird migration over southern Ontario, Canada: orientation vs. wind in autumn. In: Papi F, Wallraff HG, editors. Avian navigation. Berlin: Springer; 1982. p. 15-27.

60. Åkesson S, Walinder G, Karlsson L, Ehnbom S. Nocturnal migratory flight initiation in reed warblers Acrocephalus scirpaceus: effect of wind on orientation and timing of migration. J Avian Biol. 2002;33:349-57.

61. Bulyuk VN. Influence of fuel load and weather on timing of nocturnal spring migratory departures in European robins, Erithacus rubecula. Behav Ecol Sociobiol. 2012;66:385-95.

62. Johnson CG. Migration \& dispersal of insects by flight. London: Methuen \& Co Ltd; 1969.

63. Åkesson S, Alerstam T, Hedenström A. Flight initiation of nocturnal passerine migrants in relation to celestial orientation conditions at twilight J Avian Biol. 1996;27:95-102.

64. Liu M, Swanson DL. Stopover duration, movement patterns and temporary home ranges of fall migrant yellow-rumped warblers Setophaga coronata in native and anthropogenic woodlands of the northern prairie region, USA.J Avian Biol. 2015;46:452-61.

65. Bolshakov CV, Chernetsov N, Mukhin A, Bulyuk V, Kosarev W, Ktitorov P, Leoke D, Tsvey A. Time of nocturnal departures in European robins, Erithacus rubecula, in relation to celestial cues, season, stopover duration and fat score. Anim Behav. 2007;74:855-65.

66. Newton I. Weather-related mass-mortality events in migrants. Ibis. 2007;149: 453-67.

67. Eikenaar C, Schläfke JL. Size and accumulation of fuel reserves at stopover predict nocturnal restlessness in a migratory bird. Biol Lett. 2013;9:20130712.

68. Jenni L, Schaub M. Behavioural and physiological reactions to environmental variation in bird migration: a review. In: Berthold P, Gwinner E, Sonnenschein E, editors. Avian migration. Berlin: Springer Verlag; 2003. p. $155-71$.

69. McLaren JD, Shamoun-Baranes J, Bouten W. Stop early to travel fast modelling risk-averse scheduling among nocturnally migrating birds. J Theor Biol. 2013;316:90-8.

70. Gomez C, Bayly NJ, Norris DR, Mackenzie SA, Rosenberg KV, Taylor PD, Hobson KA Cadena CD. Fuel loads acquired at a stopover site influence the pace of intercontinental migration in a boreal songbird. Sci Rep. 2017;7:3405.

\section{Publisher's Note}

Springer Nature remains neutral with regard to jurisdictional claims in published maps and institutional affiliations.

Ready to submit your research? Choose BMC and benefit from:

- fast, convenient online submission

- thorough peer review by experienced researchers in your field

- rapid publication on acceptance

- support for research data, including large and complex data types

- gold Open Access which fosters wider collaboration and increased citations

- maximum visibility for your research: over $100 \mathrm{M}$ website views per year

At $\mathrm{BMC}$, research is always in progress.

Learn more biomedcentral.com/submissions 